\title{
Bed and bugs
}

\section{Navin Kumar Devaraj*}

Department of Family Medicine, Faculty of Medicine and Health Sciences, University Putra Malaysia, 43400, Serdang, Selangor Darul Ehsan, Malaysia

\section{Clinical image}

A 32 years old man presented with itchy urticarial lesions over his left lower leg for 3 days. The lesions are arranged in a linear fashion (Figure 1A and 1B). There was no other rash noted. There was no similar rash in the past. The patient noted that this problem also affects his wife. It all happen since they move into a new apartment they are renting since the last two weeks. On further questioning, they informed that the walls in their bedroom looks dilapidated. A diagnosis of allergic reaction secondary to bed bug bite was made. Besides treatment with oral antihistamines and moderately potent topical corticosteroids, the patient was advised to call the local pest control services to destroy the breeding site of the bed bug.

Bed bugs or the species of the Cimex group are the usual suspects in cases of linear fashion rash of either papules, urticarial or bullous lesions [1]. The assault on humans usually occurs at night. Diagnosis is straightforward with typical history of staying in homes with unkept bed or dilapidated walls and the appreciation of itchy lesions over exposed parts of the body on waking up from sleep, arranged in a linear fashion [1]. A wait and see approach or mono- or dual-therapy with oral antihistamines and topical corticosteroids can be employed, besides mandatory extermination of these bugs and their breeding sites [2].

The author declares no conflict of interest.

Copyright: (C2018 Devaraj NK. This is an open-access article distributed under the terms of the Creative Commons Attribution License, which permits unrestricted use, distribution, and reproduction in any medium, provided the original author and source are credited.
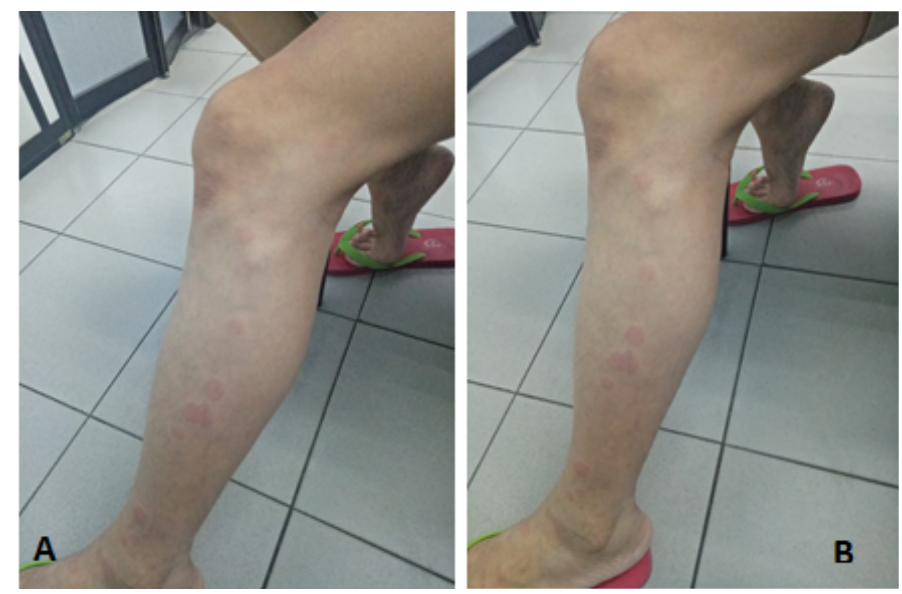

\section{References}

Figure 1. Patient with itchy urticarial lesions over his left lower leg.

1. Medscape. Bedbug Bites. Available from URL http://emedicine.medscape.com/ article/1088931-overview . Accessed on 23 August 2017

2. American Academy of Dermatology. Bedbugs. Available from URL https://www.aad. org/public/diseases/itchy-skin/bedbugs. Accessed on 23 August 2017
Correspondence to: Department of Family Medicine, Faculty of Medicine and Health Sciences, University Putra Malaysia, 43400, Serdang, Selangor Darul Ehsan, Malaysia, Tel: +603-89472538, +6013-3105381; Fax: +603-89472328, E-mail: navin59@yahoo.com

Received: January 10, 2018; Accepted: February 02, 2018; Published: February 05, 2018 